\title{
NOISE STRESS ON FEMALE MICE IMPAIR OOCYTE DEVELOPMENTAL POTENTIAL.
}

1. MBBS, M.Phil (Anatomy), Assistant Professor Department of Anatomy Army Medical College, Rawalpindi.

2. MBBS, M.Phil (Anatomy) Assistant Professor Department of Anatomy Fazaia Medical College, Air University, Islamabad

3. MBBS, FCPS (Anatomy) Assistant Professor Department of Anatomy

Army Medical College, Rawalpindi.

Correspondence Address:

Dr. Hina Kundi

Assistant Professor

Department of Anatomy

Fazaia Medical College,

Air University, Islamabad.

drhinazaid@gmail.com

Article received on:

09/06/2018

Accepted for publication:

25/09/2018

Received after proof reading:

22/05/2019

\begin{abstract}
Maria Yousaf', Hina Kundi' ${ }^{2}$, Abdullah Qamar ${ }^{3}$
ABSTRACT... To find out the effects of noise stress on variations in number of ovarian follicles in mice. Study Design: Randomized control trial. Setting: Anatomy department, Army Medical College Rawalpindi, Period: From April 2014 to May 2014. Material and Method: 20 adult mice (BALB/c strain) female weighing 25-27 grams were taken for this study on day first of their estrous cycle. Two groups comprising of 10 rats each were made. Control group was given name tag of group $A$ and was kept in animal house under normal heathy environment for one month. Noise stress of 100 decibels for 06 hours per day for one month was given to experimental group B. Mice were dissected after 1 month. Mice right ovaries were examined for size, shape, color and weight. The specimen were processed and embedded. Hematoxyline and Eosin stained slides were prepared for histological study. Follicular count (primary, secondary and tertiary follicles) was done and noted. For statistical analysis SPSS 20 was used. The tests applied was independent sample's t test for descriptive statistics. Results: There was a significant decrease in primary, secondary/antral and graafian follicular count in the ovary of Group B (Experimental). Conclusion: The noise stress prominently affected the follicular count in ovaries of noise stress treated group.
\end{abstract}

Key words: $\quad$ Follicular Count, Gonadotropic hormones, HPA axis, Ovarian Follicles, Noise, Ovary.

Article Citation: Yousaf M, Kundi H, Qamar A. Oocyte developmental; noise stress on female mice impair oocyte developmental potential. Professional Med J 2019; 26(6):951-955. DOI: 10.29309/TPMJ/2019.26.05.3603

\section{INTRODUCTION}

Increasing stress in our daily life induces many behavioral, neurobiological and endocrinological changes. ${ }^{1}$ All walksoflifeandagegroupsaresubject to it, which acutely agitates the psychological and physiological homeostasis. ${ }^{2}$ Prolonged and excessive stress is mainly a reason for disastrous effects on quality of life affecting all systems of body mainly reproductive system. Stress triggers hypothalamic-pituitary-adrenal (HPA) axis and activates sympathoadrenomedullary system, the activation depends on intensity of exposure, duration, and type. ${ }^{3}$ Anovulation results from exposure to chronic stress which finally leads to infertility because of decrease in gonadotrophic hormones levels. Chronic stress is type of stress which has frequently occurred for long duration. On comparison with acute stress, the chronic stress has more harmful effects. High stress levels is one of the causative factor for early onset of severe dysmenorhea, menopause, low birth weight and preterm labour. ${ }^{4}$ Due to the significant increase of socioeconomic problems, fast pace of urbanization and availability of limited resources especially in developing countries, there is a major shift from infectious diseases to neuropsychological disorders. ${ }^{5}$ World Health Organization (WHO) has identified that stress is one of the major etiological factors and will cause greatest global disease burden by $2020 .^{6}$ Stress related disorders affect $13 \%$ of the population every year in United States which becomes 19 million adults. As per the study of WHO, eighty percent of the deaths occur in South East Asian Countries including Pakistan and India due to the chronic stress disorders. ${ }^{7}$

Noise is the most common and potent ecological pollutant. The 20th century has been nominated as the century of noise. Noise has a vast impact on quality of life. Not only does it affects the auditory efficiency but also perturbs endocrine and 
reproductive system. ${ }^{8}$ The noise and sound have similar characteristics as regards their perception and propagation is concerned. Noise is the undesirable waveform which leads to unease to the listener. It is one of the reasons for decrease in reproductive ability and also had deteriorating effect on developing embryos that are exposed to high frequency noise. ${ }^{9}$ Teratogenic effects of noise include increased pre-implantation mortality, decrease embryo weight and size, fetal hypoxia, increased secretion of maternal catecholamine, decreased embryo weight and size and decreased litter size. ${ }^{1}$

Our study rationale is to determine the effects of noise stress on three types of ovarian follicles.

\section{MATERIAL AND METHODS}

The study was conducted in department of anatomy at Army Medical College Rawalpindi. It was collaborated with National Institute of Health $(\mathrm{NIH})$, Islamabad. The experiment was laboratory based randomized control trial during the months of April and May 2014. Ethical approval was taken from the ethical committee of Army Medical College, Rawalpindi. Twenty adult, nonpregnant female BALB/c mice five to seven weeks old with weight ranging from $25 \mathrm{gms}$ to $27 \mathrm{gms}$ were used in the experiment. Two groups of mice were made and were fed on normal mice feed of $\mathrm{NIH}$ laboratory for 1 month. Animals in Group A was labeled as control group and were kept in animal house's healthy environment for the period of 1 month. The experimental Group B were exposed to pure tone noise stress of 100 decibels for 06 hrs per day for one month. ${ }^{9}$ In order to measure and sustain a constant intensity of noise a sound level decibel meter was used. The intensity of sound was measured with sound level meter (Radioshack analogue model 33-4050). It was placed outside the cages. Intensity of sound was recorded at the start at end of the experiment. At the end of one month, the animals were euthanized and dissected. The ovaries was dissected out. Right ovary of each mice taken in account in order to maintain uniformity. Specimen were weighed. Size, shape and color of ovaries were noted. Ovaries were then placed in formalin 10\% solution in labelled plastic containers. 5 microns thick sections tissue sections were made with the help of rotary microtome. Hematoxylin and Eosin $(\mathrm{H}$ and $\mathrm{E})$ staining of section was done with the help of autostainer. The Primary, secondary/antral and graafian follicles were counted and noted. Three slides for each specimen were observed. ${ }^{11}$ Objective power of 10X was used for the counting of number of different types of follicles. Following classification was used to see the follicular structure and morphology. ${ }^{12}$

Primary follicle designated as (FI) contains an oocyte wholly surrounded by one or multiple layers of cuboidal cells and a zona pellucida in between occyte and cuboidal epithelium.

Secondary follicle or antral follicle designated as (FII) is oocyte enclosed by multiple layers of cuboidal cells with tiny spaces or antrum between these cell layers and a zona pellucida in between oocyte and cuboidal cells.).

Graafian follicle or mature follicle or tertiary follicle designated as (FIII) is an oocyte surrounded by zona pellucida, multiple layers of granulosa cells with one large antrum).

\section{Statistical Analysis}

Version 20 of Statistical Package for Social Sciences SPSS was used to analyze data. Descriptive statistics was applied to explain the results. For comparisons of primary, secondary and graafian follicles, Independent sample's $t$ test was applied. Results with $p<0.05$ were considered significant.

\section{RESULTS}

Ovaries obtained from the animal in control group (A) were firm in texture and pale to whitish in color. Shape of ovaries in control group (A) appeared round in three animals and ellipsoid in seven animals. Each ovary had a normal histological structure having an outer covering of germinal epithelium with simple cuboidal epithelium. Beneath the germinal epithelium was thick connective tissue layer containing collagen fibers forming tunica albuginea. The ovarian tissue had an outer cortex containing the follicles at different stages of development and the inner medulla 
containing stroma and blood vessels (Figure1a). Color of ovary in experimental group $B$ was reddish in 01 animal while in 09 animals was pale whitish. Shape of ovaries in experimental group B appeared as round in 04 animals and ellipsoid in 06 animals. Microscopically, noise stress resulted in slight decrease in ovarian follicular count and disturbed follicular structure with decrease in granulosa cell layer and increase numbers of theca cell layer as compared to control group A. No inflammation or adhesions were observed.

The mean ovary weight of group (A) animal was $0.0185 \mathrm{gm}(\mathrm{SD}=0.000527$ ) (in accordance with our previous article) ${ }^{13}$ and in experimental group (B) was $0.0183 \mathrm{gm}(\mathrm{SD}=0.000483)$. The mean

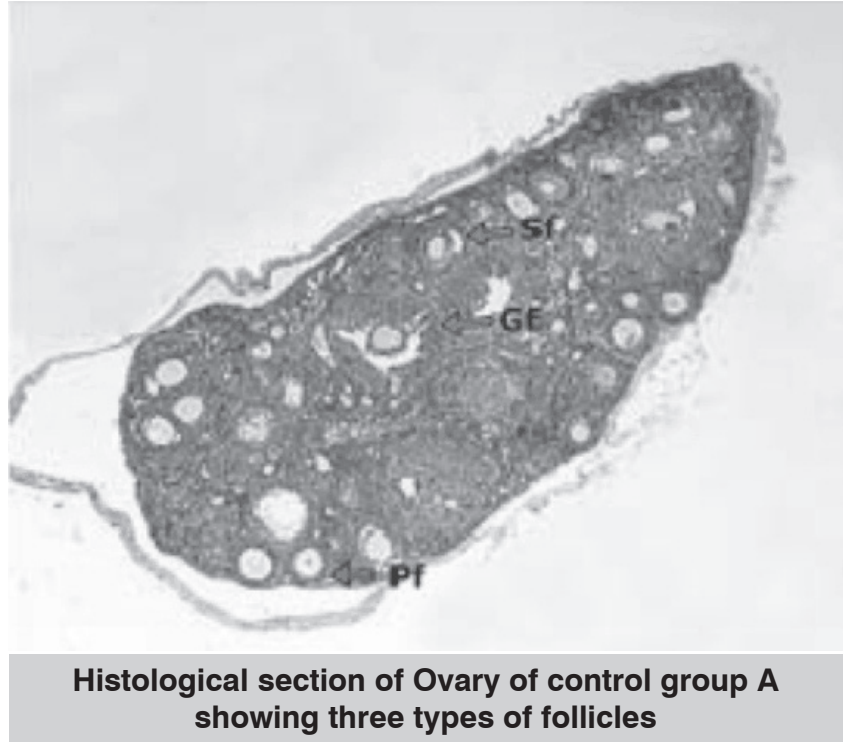

weight of ovary in experimental group (B) was significantly less then control group (A) with a p-value of $<0.001$.

Mean number of $\mathrm{Fl}$ in control group (A) was 12.5 $(\mathrm{SD}=2.37)^{13}$, in experimental group $(\mathrm{B})$ it was $9.8(S D=1.03)$. The $p$-values were 0.002 which was statistically significant. In control group (A) mean number of Fll was $8.9(\mathrm{SD}=1.20)^{13}$, in experimental group (B) was $6(\mathrm{SD}=0.816)$. The p-values was 0.403 which was statistically insignificant. Regarding the number of Flll; 2 (20\%) mice had 3 graafian follicles, 2 (20\%) mice had 2 graafian follicles, $5(50 \%)$ mice had 1 graafian follicle and 1 (10\%) mice had no graafian follicle. (Table-l)

Histological section of Ovary of Experimental group B showing three types of follicles

Figure-1. Photomicrograph at showing Pf (Primary follicle), Sf (Secondary Follicle), Gf (Graafian Follicle) and $(\mathrm{Cl})$ Corpus Luteum in group $(\mathrm{A})$ and group $(\mathrm{B})$. (H\&E x 100)

\begin{tabular}{|c|c|c|c|c|c|c|}
\hline & \multicolumn{2}{|c|}{ (FI) } & \multicolumn{2}{c|}{ (FII) } & \multicolumn{2}{c|}{ (FIII) } \\
\hline Animal number & Group A & Group B & Group A & Group B & Group A & Group B \\
\hline 1 & 18 & 10 & 5 & 5 & 2 & 1 \\
\hline 2 & 14 & 11 & 7 & 6 & 3 & 2 \\
\hline 3 & 13 & 11 & 5 & 7 & 2 & 0 \\
\hline 4 & 10 & 10 & 8 & 5 & 0 & 3 \\
\hline 5 & 11 & 9 & 6 & 7 & 2 & 1 \\
\hline 6 & 11 & 11 & 9 & 6 & 3 & 3 \\
\hline 7 & 10 & 9 & 5 & 6 & 3 & 1 \\
\hline 9 & 12 & 8 & 7 & 7 & 2 & 1 \\
\hline 10 & 13 & 10 & 7 & 6 & 3 & 1 \\
\hline
\end{tabular}




\section{DISCUSSION}

Stress comprises the biological occurrences which are not specific and are outcome of the happenings which suppress the homeostasis and severely weaken the individual mental as well as physical health. ${ }^{14}$ Day to day stress is increasing in severity and magnitude due to increased industrialization and urbanization. Statistically significant results were observed when mean value of ovarian weight was compared between groups.

Ovarian tissue is an aggregate of stroma, growing follicles and corpus luteum. All three constitute the net weight of ovary. Reduction in ovarian weight of stressed animals is due to inadequate release of gonadotrophic or steroidal hormones or both. ${ }^{15}$ Consistency of ovaries were firm and appeared similar in shape as in control group A. Number of follicles present in ovary represents its functional status. This plays an important role in the determination of various sex hormones such as gonadotrophins and intraovarian growth factor responsible for regulating follicular survival and different stages of its maturation. ${ }^{16}$ Regarding the number of $\mathrm{FI}$, the result was statistically significant between the group (A) and group (B). Previous studies demonstrated the stress induced changes in development of follicles in animal models like sheep, cattle and rodents. Even under stressful conditions maturation of follicles continues but compromised ovarian function was indicated by variation in ovarian follicular count. ${ }^{17}$

Results were found statistically significant when primary follicles and graffian follicles were observed but the difference was statistically insignificant when secondary follicles of group (A) was compared with group (B). From the above mentioned findings it is concluded that the stress not only causes decrease in the number of follicular count but also affects the quality of oocyte and decline reproductive ability of female mice. Therefore, survival and development of follicles are directly proportional to any type of stress. Stress depresses the hypothalamus-pituitaryovarian axis due to activated hypothalamuspituitary-adrenocortical axis, resulting in reduced $\mathrm{LH}$ and FSH levels. These hormones acts upon germinal epithelium and plays an important role in cell development and maturation. ${ }^{18}$ Our results are in line with the previous studies regarding stress.

\section{CONCLUSION}

The present study concludes the exposure to noise stress results in reduction in number of primary, secondary/ antral and graafian follicles in ovaries significantly.

\section{CONFLICT OF INTEREST}

National University of Sciences and Technology Islamabad partially funded the research.

Copyright@ 25 Sep, 2018.

\section{REFERENCES}

1. Nayanatara A, Nagaraja $H$, Anupama B. The effect of repeated swimming stress on organ weights and lipid peroxidation in rats. Thai J Pharm Sci. 2005; 18(1): 3-9.

2. Saraswathi C, Sreemantula S, Prakash WS. Effect of chronic cold restraint and immobilization stress on estrous cycle in rats. Pharmacology Online. 2010; 2(3): 151-60.

3. Ruder EH, Hartman TJ, Blumberg J, Goldman MB. Oxidative stress and antioxidants: Exposure and impact on female fertility. Human reproduction update. 2008; 14(4): 345-57.

4. McEwen, B. S. Protection and damage from acute and chronic stress: Allostasis and allostatic overload and relevance to the pathophysiology of psychiatric disorders. Annals of the New York Academy of Sciences, 2004;1032(1): 1-7.

5. Berry, H. L., Bowen, K. and Kjellstrom, T. Climate change and mental health: A causal pathways framework. International Journal of Public Health, 2010;55(2): 123132.

6. Waxman, A. Why a global strategy on diet, physical activity and health?, Journal of Nutrition and Fitness, 2005;95(5): 232-237.

7. Saha, S., Gandhi, A., Das, S., Kaur, P. and Singh, $S$. Effect of noise stress on some cardiovascular parameters and audiovisual reaction time. Indian Journal of Physiology and Pharmacology, 1996;40(1): 35-40.

8. Pramanik, P. and Biswas, S. Traffic noise: A silent killer of male gamate of albino rats. American Journal of Medical Sciences, 2012;5(1): 82-89. 
9. Diab, A., Hendawy, A., Asala, A., Ibrahim, S. and Hassan, $M$. Effect of noise stress on pituitary gonadal axis in albino rats. Journal of American Science, 2012;8(11): 198-202.

10. Fathollahi, A., Jasemi, M. and Saki, G. Effect of noise stress on male rat fertility, and the protective effect of vitamins $\mathbf{C}$ and $\mathbf{E}$ on its potential effect. Arab Journal of Urology, 2013;11(1): 101-105.

11. Jensen, F., Willis, M. A., Leopardo, N. P., Espinosa, M. B. and Vitullo, A. D. The ovary of the gestating South American plains vizcacha (Lagostomus maximus): suppressed apoptosis and corpora lutea persistence. Biology of reproduction, 2008;79(2): 240246.

12. De Ratones, C. H. D. O. Histological changes of the ovary of adult mice exposed prenatally to flunitrazepam. International Journal of Morphology, 2006;24(4): 651-658.

13. Yousaf $M$, Siddiqi $H$, Waheed N. Histomorphological effects of hunger stress on ovaries. Journal of Ayub Medical College Abbottabad. 2017;29(4):654-7.
14. Shugaba, A., Asala, A., Gambo, I., Mohammed, B., Shinku, F., Rabiu, A., Uzokwe, C., Hambolu, J. and Ojo, $S$. The effects of physical and oxidative stress on the ovary of the female wistar rat. Journal of Biological Chemistry, 2012;29(2): 326-335.

15. Saraswathi, C., Sreemantula, S. and Prakash, W. S. Effect of chronic cold restraint and immobilization stress on estrous cycle in rats. Pharmacologyonline, 2010;2:151-60.

16. Myers, M., Britt, K., Wreford, N., Ebling, F. and Kerr, J. Methods for quantifying follicular numbers within the mouse ovary. Reproduction, 2004;127: 569-580.

17. Abdullah, K. H. Effect of stress hormone antagonists on ovarian follicular development in pre-pubertal rat. Journal of Stress Physiology and Biochemistry, 2012;8(3): 82-98.

18. Liang, B., Wei, D.-L., Cheng, Y.-N., Yuan, H.-J., Lin, J., Cui, X.-Z., Luo, M.-J. and Tan, J.-H. Restraint stress impairs oocyte developmental potential: Role of CRH-induced apoptosis of ovarian cells. Biology of Reproduction: 2013;113-144.

\begin{tabular}{|c|c|c|c|}
\hline \multicolumn{4}{|c|}{ AUTHORSHIP AND CONTRIBUTION DECLARATION } \\
\hline Sr. \# & Author-s Full Name & Contribution to the paper & Author $=\mathbf{s}$ Signature \\
\hline 1 & Maria Yousaf & $\begin{array}{l}\text { Conception of idea, Design of study, } \\
\text { Data collection \& Analysis of data } \\
\text { Histomorphological evaluation. }\end{array}$ & maira 7 ous of \\
\hline 2 & Hina Kundi & $\begin{array}{l}\text { Microscopic slides evaluation, } \\
\text { Microphotographs, Interpretation of } \\
\text { resluts. }\end{array}$ & Yiu 2000 \\
\hline 3 & Abdullah Qamar & $\begin{array}{l}\text { Interpretation of data SPSS } \\
\text { Statsitical analysis Interpretation of } \\
\text { results. }\end{array}$ & $A Q$ \\
\hline
\end{tabular}

